\title{
Development of Novel Methodology Using Diazo Compounds and Metal Catalysts
}

\author{
Shingo Harada \\ Graduate School of Pharmaceutical Sciences, Chiba University; \\ 1-8-1, Inohana, Chuo-ku, Chiba 260-8675, Japan.
}

Received August 31, 2021

\begin{abstract}
The ability to control the reactions of highly active chemical species to enable straightforward synthesis of valuable compounds such as bioactive natural products and pharmaceuticals is a continuing challenge in synthetic organic chemistry. This review describes the development of a methodology using reactive metalcarbene species and its synthetic application in our laboratory. First, regioselective synthesis of $\gamma$-amino acid equivalents to take advantage of their metal-dependent reactivities and the mechanistic rationale are presented. Chemoselective and enantioselective dearomatization reactions of several arenes with silver-carbene are also discussed. In the second half of the review, we discuss a carbene-insertion reaction into an amide and urea $\mathrm{C}-\mathrm{N}$ bond for the assembly of nitrogen-bridged cyclic molecules.
\end{abstract}

Key words carbene; diazo compound; silver; rhodium; catalyst

\section{Introduction}

A carbene is an electrically neutral carbon species that possesses two unshared valence electrons and is bonded to two univalent groups or a divalent group. The recently redefined nomenclature for metal-carbenes and related species is followed in this review ${ }^{1,2)}$ (Fig. 1).

Metal-carbenes are highly active carbon species that lead to unique reaction manifolds, such as $\mathrm{C}-\mathrm{H}$ insertion reactions, alkene cyclopropanation, and ylide formation. ${ }^{3-8)}$ There are a number of valuable molecular transformations that cannot be achieved without the use of carbene species that are applied to the synthesis of pharmaceuticals and bioactive natural products. The reactivities and observed selectivities of metal-carbenes depend on the metal identity of the employed catalysts, but the origin of the selectivity differences remains elusive. The present review describes the contributions of our research group to the field as follows: 1) controlling multi-selectivities by taking advantage of specific properties of metal-carbene species, and 2) developing a new class of carbene-insertion reactions.

\section{Selective Reactions Using Diazo Compounds and Silver Catalysts}

2.1. Regioselective Hydroamination of Alkenyl Diazoacetates The molecular structural unit of $\gamma$-aminobutyric acid (GABA) constitutes a crucial substructure of bioactive molecules, including the inhibitory neurotransmitter in the central nervous system. Synthetic efforts directed toward $\gamma$-amino acids are, however, quite limited compared with $\alpha$ -

This review of the author's work was written by the author upon receiving the 2021 Pharmaceutical Society of Japan Award for Young Scientists. and $\beta$-amino acids. Diazo compounds with an alkenyl group could be transformed into metal-carbenes that display electrophilic properties at the vinylogous position along with the usual reactivity of metal-carbenes. We attempted to control the regioselectivity between the $\alpha$-position $(\mathrm{N}-\mathrm{H}$ insertion) and $\gamma$-position (vinylogous hydroamination) in the reaction with nitrogen nucleophiles by selecting the appropriate metal catalyst for the synthesis of $\gamma$-amino acid derivatives ${ }^{9)}$ (Table 1). A rhodium acetate catalyst, which is commonly used in metal-carbene reactions, dominantly promoted the $\mathrm{N}-\mathrm{H}$ insertion reaction, giving $\alpha$-amino acid variants (4a, entry 1 ). While almost no target product 3a was isolated under copper or gold catalysis (entries 2 and 3), a complete regioselectivity switch was observed when using silver tetrafluoroborate catalyst $^{10)}$ (entry 4).

The substrate applicability to the synthesis of an array of $\gamma$-amino acid derivatives 3 was examined and is summarized in Fig. 2. Functionalized $\gamma$-adducts with arenes having an electron-donating or electron-withdrawing group at the ortho,

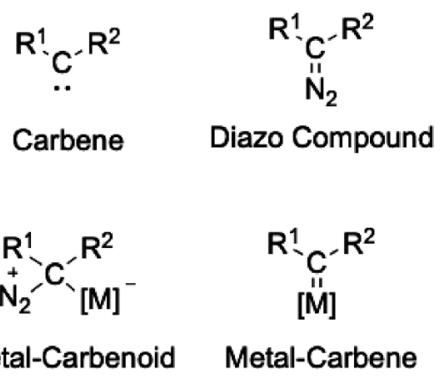

Fig. 1. Nomenclature for Metal-Carbenes and Related Species 
Table 1. Metal Screening for Hydroamination

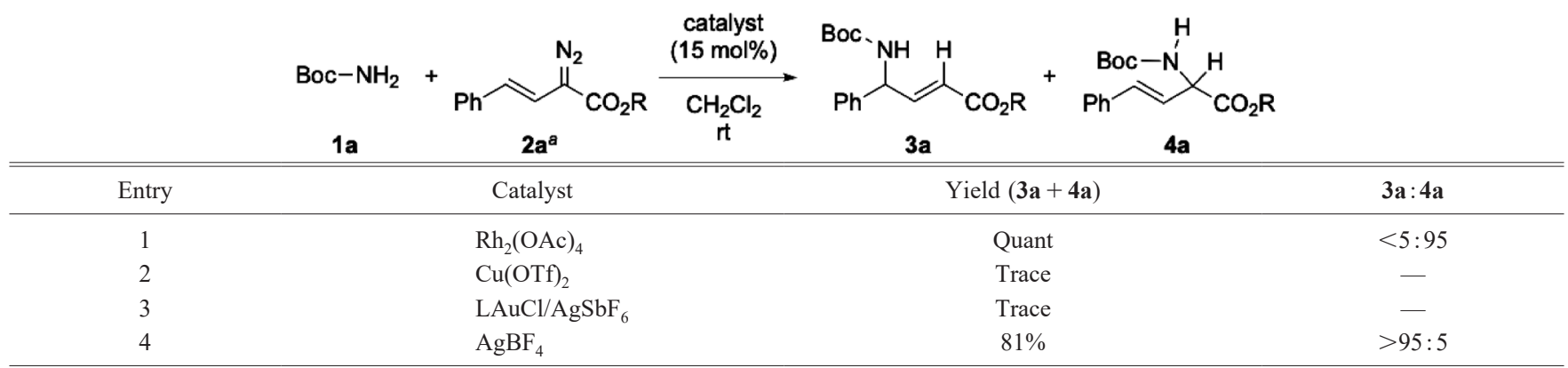

${ }^{a}$ A solution of $2 \mathbf{a}$ in $\mathrm{CH}_{2} \mathrm{Cl}_{2}$ was added drop-wise over $2 \mathrm{~h}$. R represents $\mathrm{CH}_{2} \mathrm{CCl}_{3}$. L represents $\mathrm{P}\left[\mathrm{O}\left(2,4-t-\mathrm{Bu}_{2} \mathrm{C}_{6} \mathrm{H}_{3}\right)\right]_{3}$.

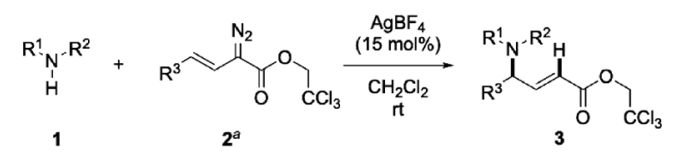

(n)

Fig. 2. Substrate Scope of Ag-Catalyzed Regioselective Hydroamination

\footnotetext{
${ }^{a}$ A solution of 2 in $\mathrm{CH}_{2} \mathrm{Cl}_{2}$ was added drop-wise over 2 h. r.s. represents the ratio of the $\gamma$-adduct to the $\alpha$-adduct.
}

meta, or para-positions were furnished in moderate to good yields with regiocontrol $(\mathbf{3 b}-\mathbf{h})$. A secondary amine was also available for silver catalysis, providing the corresponding (E)- $\gamma$-amino $\alpha, \beta$-unsaturated ester (3k).

To shed light on the origin of the catalyst-dependent regioselectivity, quantum computational analysis was performed based on density functional theory (Fig. 3). The overall activation energy for $\gamma$-attack of the carbamate to generate $\mathbf{I N} \mathbf{N}_{\gamma \text { - } \mathbf{A g}}$ from $\mathbf{S M}_{\mathbf{A g}}$ and $\mathbf{1 b}$ was $10.8 \mathrm{kcal} / \mathrm{mol}\left(\mathbf{T S}_{\gamma-\mathbf{A g}}\right.$, [A]), which was lower than that of $\alpha$-attack $\left(\mathbf{T S}_{\alpha \text {-Ag }}\right)$. Intriguingly, multipoint interactions between $\mathrm{F}$ and $\mathrm{H} / \mathrm{Ag}$ were operative in the model of $\mathbf{T S}_{\gamma \text {-Ag }}$, contributing to the preference for $\gamma$-selectivity. For the $\mathrm{Rh}$-catalyzed reaction [B], an attack at the $\gamma$-position $\left(\mathbf{T S}_{\gamma-\mathbf{R h}}, \Delta G^{f}=16.5 \mathrm{kcal} / \mathrm{mol}\right)$ was $+7.8 \mathrm{kcal} / \mathrm{mol}$ less favorable than the transition model of $\mathbf{T S}_{\alpha-\mathbf{R h}}$, where a hydrogen bonding interaction acts between the carbamate $\mathrm{NH}$ and oxygen atoms in the ester unit.

2.2. Chemoselective Dearomatization of Arenes A functional-group selective transformation enhances the efficiency of synthetic routes by reducing the number of additional steps for tedious protection/deprotection sequences and minimizing undesired side products. Engineering chemoselectivity in a divergent reaction system using highly reactive species such as metal-carbenes, however, remains a tough

\section{Biography}

Shingo Harada was born in Osaka, Japan, in 1985. He received his Bachelor of Science (2008) under the supervision of Professor Yoshiki Morimoto, a Master of Science (2010) under the supervision of Professor Kiyoshi Tomioka, and a doctoral degree (2013) from Kyoto University under the supervision of Professor Kiyosei Takasu. In 2013, he began his professional academic career as an assistant professor in Professor Yasumasa Hamada's and Professor Tetsuhiro Nemoto's group at Chiba University. During this period, he worked as a visiting scientist with Professor Harald Gröger's group at Bielefeld University in 2017. In addition, he worked as a visiting scientist with Professor Timothy Newhouse's group at Yale University in 2019. In 2020, he was promoted to lecturer. He has received several awards, including The Pharmaceutical Society of Japan, Kinki Branch Award for

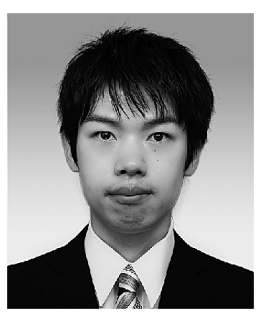

Shingo Harada Young Scientists (2013), Chugai Award in Synthetic Organic Chemistry, Japan (2017), and The Pharmaceutical Society of Japan Award for Young Scientists (2021). His research interests include metal-carbene chemistry and complex molecule synthesis. 

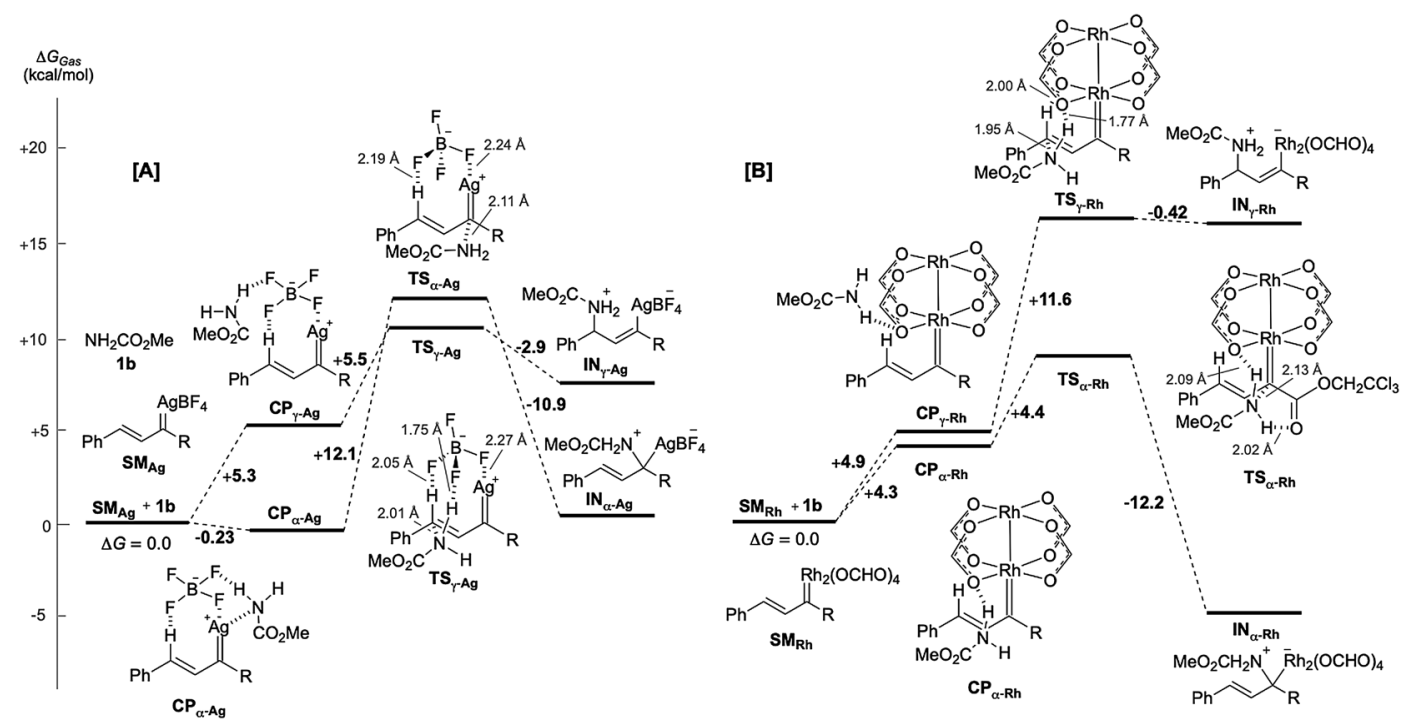

Fig. 3. Relative Energies for the Hydroamination Reaction of Ag-Carbene [A] and Rh-Carbene [B] Calculated at the M06/6-31G* \& LANL2DZ Level of Theory

$\mathrm{R}$ represents $\mathrm{CO}_{2} \mathrm{CH}_{2} \mathrm{CCl}_{3}$.
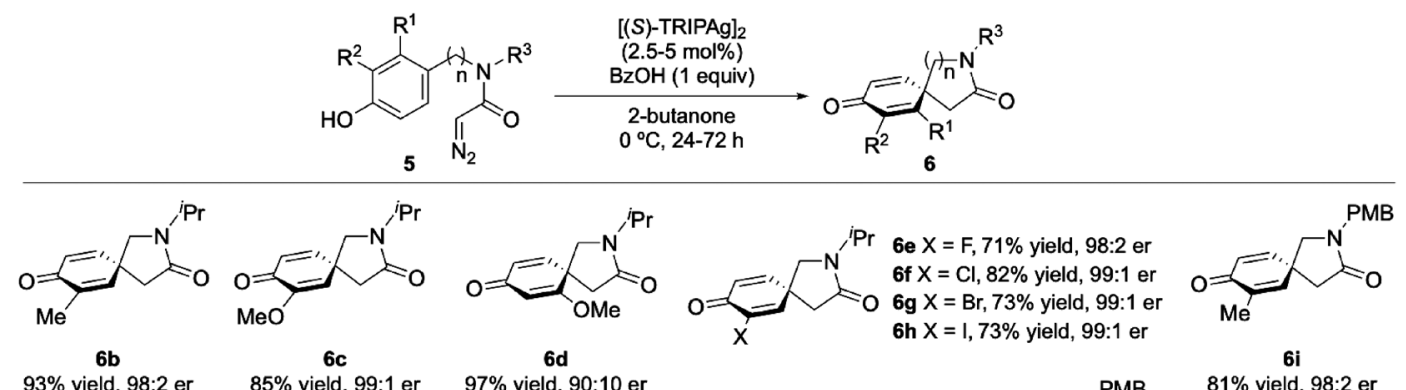

$93 \%$ yield, $98: 2$ er $\quad 85 \%$ yield, $99: 1$ er $\quad 97 \%$ yield, $90: 10$ er

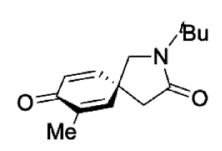

6j

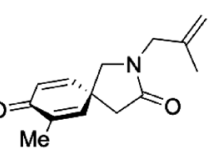

6k

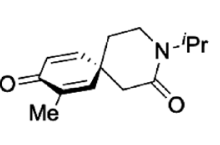

6l

$80 \%$ yield, $97: 3$ er $\quad 91 \%$ yield, $97: 3$ er $\quad 63 \%$ yield, $98: 2$ er

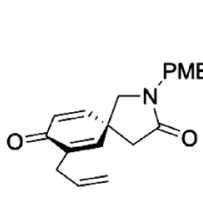

$6 \mathrm{~m}$

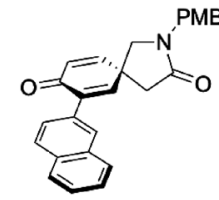

6n

$96 \%$ yield, $98: 2$ er

$81 \%$ yield, $98: 2$ er

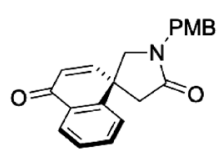

60

$34 \%$ yield, $94: 6$ er

Fig. 4. Scope of Phenol Dearomatization under Silver Catalysis

PMB represents para-methoxybenzyl.

Table 2. Optimization of Reaction Conditions

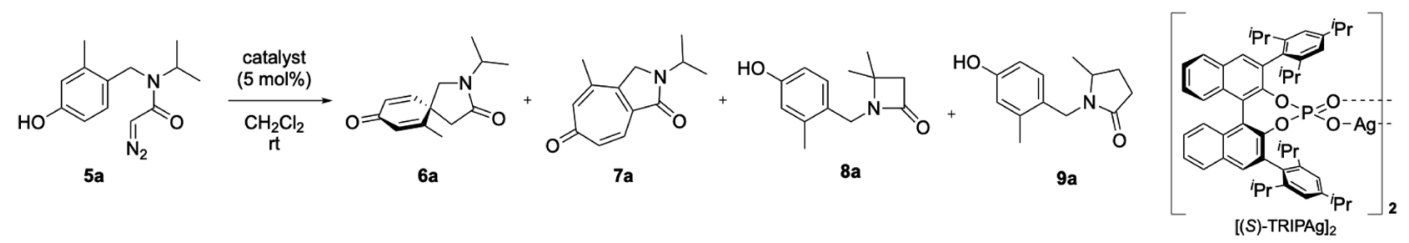

\begin{tabular}{|c|c|c|c|c|c|c|}
\hline \multirow{2}{*}{ Entry } & \multirow{2}{*}{ Catalyst } & \multicolumn{4}{|c|}{ Yield (\%) } & \multirow{2}{*}{ er of $\mathbf{6 a}(R: S)$} \\
\hline & & $6 \mathbf{a}$ & $7 \mathbf{a}$ & $8 a$ & 9a & \\
\hline 1 & $\mathrm{Rh}_{2}(\mathrm{OAc})_{4}$ & 0 & 26 & 17 & 15 & - \\
\hline 2 & $\mathrm{Cu}(\mathrm{MeCN})_{4} \mathrm{PF}_{6}$ & 6 & 20 & 16 & 25 & - \\
\hline 3 & $(\mathrm{ArO})_{3} \mathrm{PAuCl} / \mathrm{AgSbF}_{6}$ & 52 & 0 & 0 & 0 & - \\
\hline $4^{a}$ & $(\mathrm{ArO})_{3} \mathrm{PAuCl} /[(S)-\mathrm{TRIPAg}]_{2}$ & 84 & 0 & 0 & 0 & $28: 72$ \\
\hline $5^{a}$ & {$[(S)-\mathrm{TRIPAg}]_{2}$} & 51 & 15 & 0 & 0 & $81: 19$ \\
\hline $6^{a, b}$ & {$[(S)-\text { TRIPAg }]_{2}$} & 89 & 0 & 0 & 0 & $95: 5$ \\
\hline
\end{tabular}

${ }^{a} 2.5 \mathrm{~mol} \%$ of $[(S) \text {-TRIPAg }]_{2}$ was used. ${ }^{b}$ Reaction was performed using 1 equivalent (equiv) of $\mathrm{BzOH}$ at $0{ }^{\circ} \mathrm{C}$ in 2-butanone solvent. $\mathrm{Ar}$ represents $2,4-t-\mathrm{Bu}_{2} \mathrm{C}_{6} \mathrm{H}_{3}$. 
challenge. Arene dearomatization reactions ${ }^{11-13)}$ are powerful strategies for constructing three-dimensional molecules from easily accessible aromatic feedstocks. ${ }^{14-17)}$ Our group envisioned that chemoselective arene dearomatizations could be designed by applying an electrophilic metal-carbene if the competing $\mathrm{C}-\mathrm{H}$ insertion and Buchner ring expansion could be suppressed by suitable selection of the metal-center and supporting ligands. Firstly, diazoamide 5a having $1^{\circ}, 2^{\circ}$ and $3^{\circ} \mathrm{C}-\mathrm{H}$ bond near the reaction site was prepared to assess chemoselectivity $^{18-20)}$ (Table 2). The reaction employing a rhodium or copper complex provided a mixture of $\mathrm{C}-\mathrm{H}$ insertion products $8 \mathbf{a}$ and $\mathbf{9 a}$, and tropone variant $\mathbf{7 a}$ through a Buchner
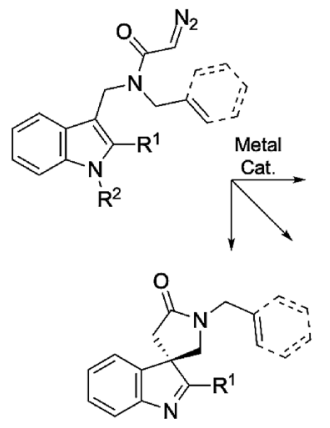

Dearomative Spirocyclization
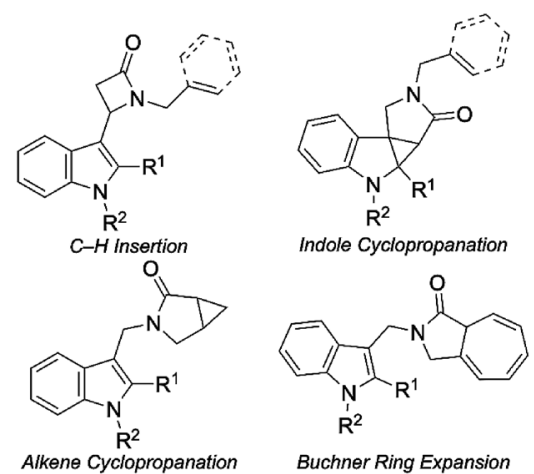

Indole Cyclopropanation

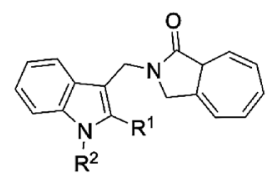

Buchner Ring Expansion
Fig. 5. Diverse Reactions Using Metal Catalysts and Indoles with Diazo Functionality reaction (entries 1 and 2). In addition, the use of a gold or silver catalyst in the system chemoselectively afforded dearomatized products 6a (entries 3 and 4). After further examining the reaction conditions (entry 6), the substrate scope of the chemoselective dearomatization reaction was investigated (Fig. 4).

In previous studies of the dearomative spirocyclization of phenols, the presence of substituents at the meta-position of phenols was prerequisite to achieve effective discrimination of the $\mathrm{Re} / \mathrm{Si}$ face of the carbon at the para-position. As exemplified by $\mathbf{6 b}-\mathbf{c}$ and $\mathbf{6 e}-\mathbf{j}$, electron-rich and electron-deficient ortho-substituted phenols were also applicable to the asymmetric dearomatization. The potentially reactive olefin functionality remained intact in the spirocyclization without side reactions such as a cyclopropanation reaction $(6 \mathbf{k}$ and $\mathbf{6 m})$. It is noteworthy that the pivotal structure of the spirolactam with an all-carbon quaternary stereogenic center is ubiquitous in pharmaceutical compounds. ${ }^{21)}$

Next, chemoselective dearomatization of other aromatics using metal-carbene species was examined. ${ }^{22,23)}$ Previous studies describe that reactions between indole variants and metalcarbenes provide a wide variety of products via $\mathrm{C}-\mathrm{H}$ insertion or cyclopropanation. etc., but controlling the chemoselectivity and enantioselectivity remain a challenging aspect (Fig. 5).

Similar reaction conditions with phenol dearomatization could be applied to reactions of indole 11, furnishing an array of enantioenriched spiroindolenines (Fig. 6). It should be

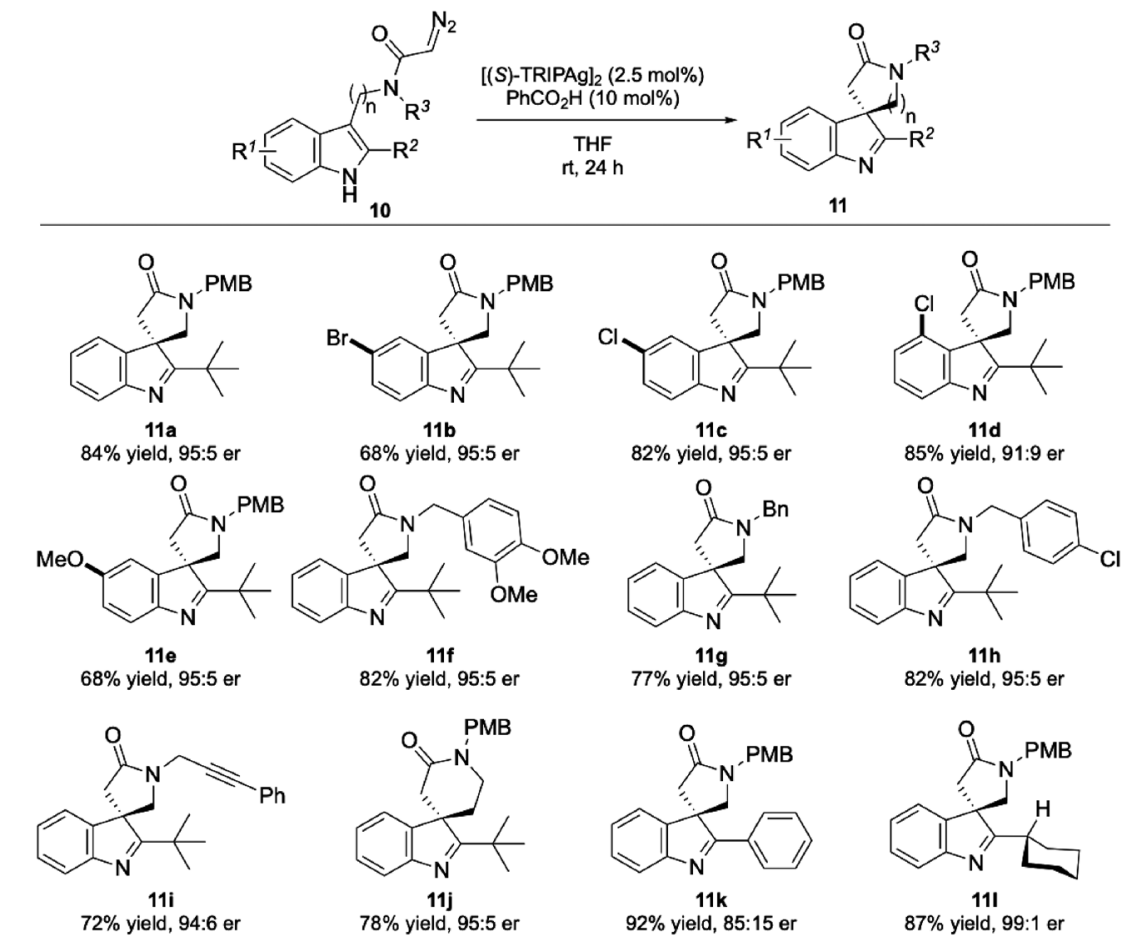

Fig. 6. Dearomative Spirocyclizations of Indoles with Bulky Substituents at the 2-Position
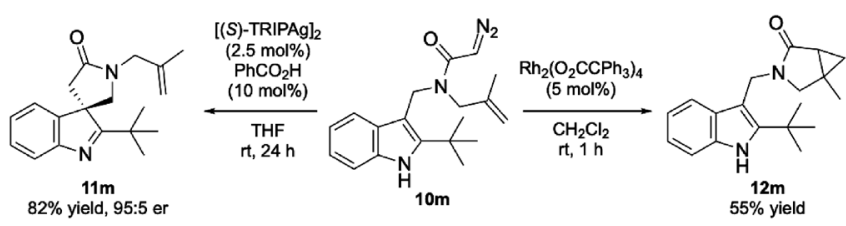

Fig. 7. Catalyst-Dependent Chemoselectivity 
i)

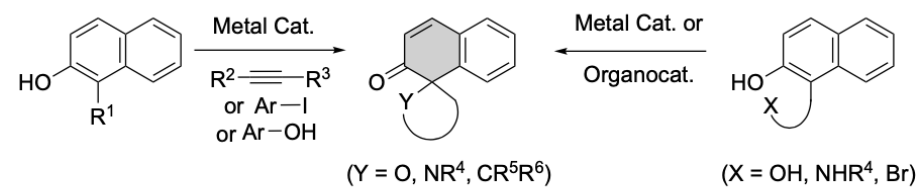

ii)

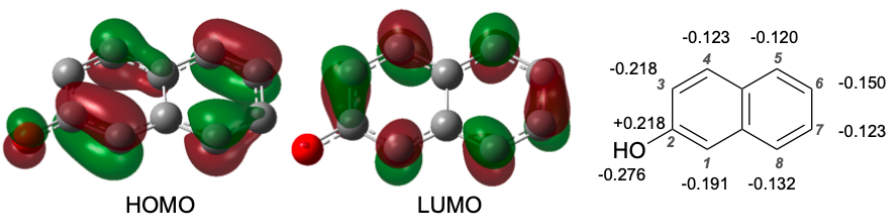

iii)

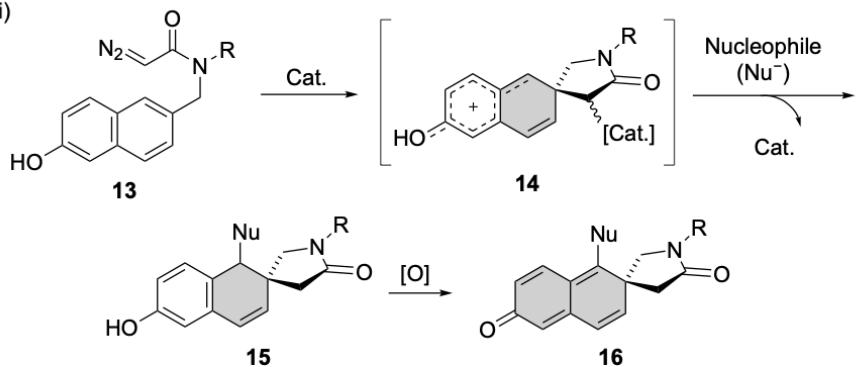

Fig. 8. (i) Conventional Reactions for the $\beta$-Naphthols Dearomatization; (ii) Frontier Orbitals and Charge Distribution; (iii) Our Reaction Design (Color figure can be accessed in the online version.)
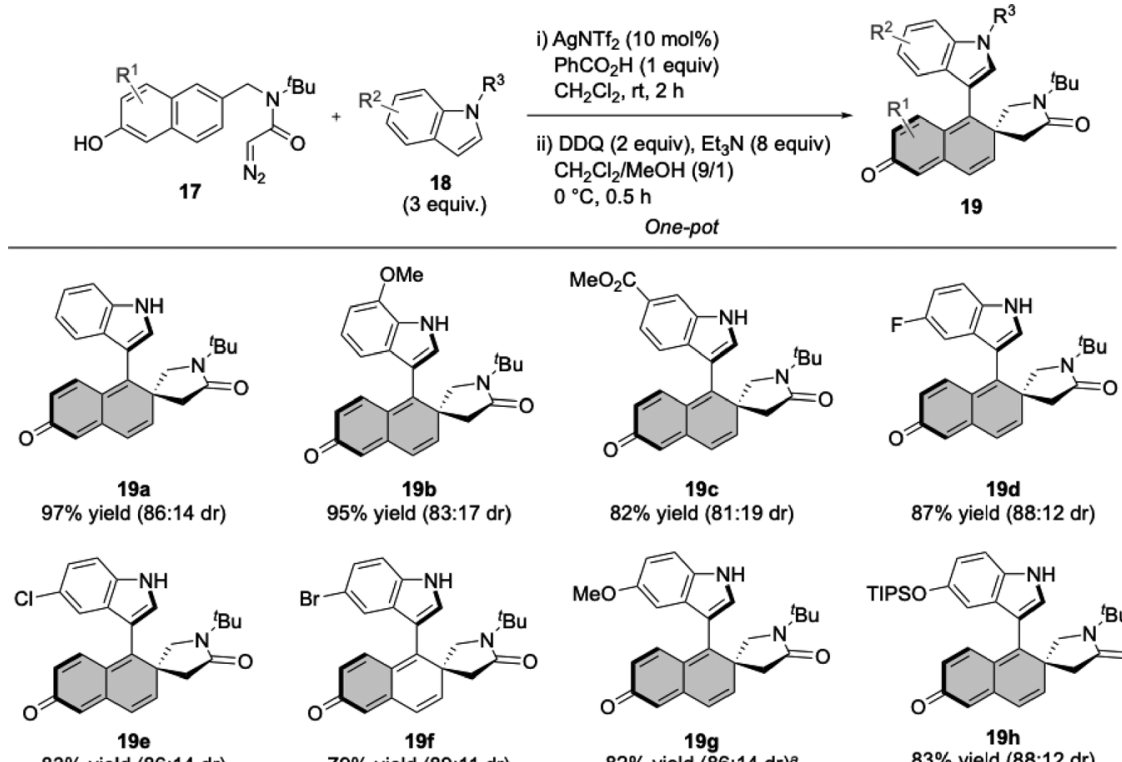

$83 \%$ yield $(86: 14 \mathrm{dr})$ $19 f$
$79 \%$ yield $(89: 11 \mathrm{dr})$
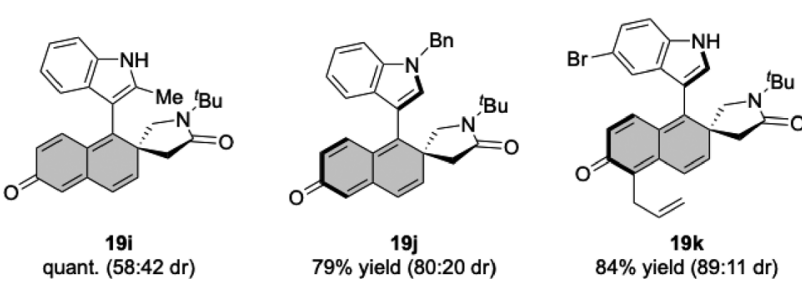

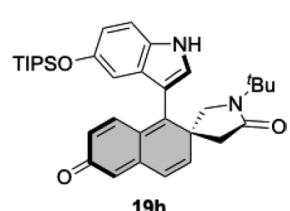

$83 \%$ yield $(88: 12 \mathrm{dr})$

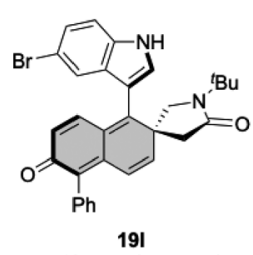

$74 \%$ yield $(87: 13 \mathrm{dr})$

Fig. 9. Scope of Double Dearomatization

${ }^{a} 3$ equiv of DDQ was used. DDQ represents 2,3-dichloro-5,6-dicyano-1,4-benzoquinone.

noted that bulky substituents at the 2-positions of indoles were essential for effective enantiodiscrimination, otherwise, poor asymmetric induction was observed.

A competitive reaction between intramolecular olefin cy- clopropanation and spirocyclization under rhodium and silver catalysis was implemented, exhibiting a striking inversion of chemoselectivity $^{24)}$ (Fig. 7).

$\beta$-Naphthol variants have gained attention recently as ben- 


$$
\text { Insertion }
$$

Fig. 10. Carbene-Insertion Reaction into Various Bonds eficial starting compounds because their dearomative transformation enables direct syntheses of benzo-fused spirocycles. In already established strategies, the dearomatization of $\beta$-naphthols was on the basis of coupling reactions, lactonization, or amination, etc. (Fig. 8(i)). These reactions occur at the $\mathrm{C} 1$ position of naphthols because of their inherent nature, dearomatizing the phenol part of $\beta$-naphthols. Before conducting actual experiments, we computationally analyzed the frontier orbitals and Mulliken charge distribution of $\beta$-naphthol, which exhibited overlooked reactivity at the C6 position ${ }^{25)}$ (Fig. 8(ii)). The reaction course shown in Fig. 8(iii) was then designed using a diazo compound $\mathbf{1 3}$ and metal catalyst to generate key reaction species. The generated dearomatized intermediate $\mathbf{1 4}$ would be usable for further bond formation by trapping with nucleophiles.

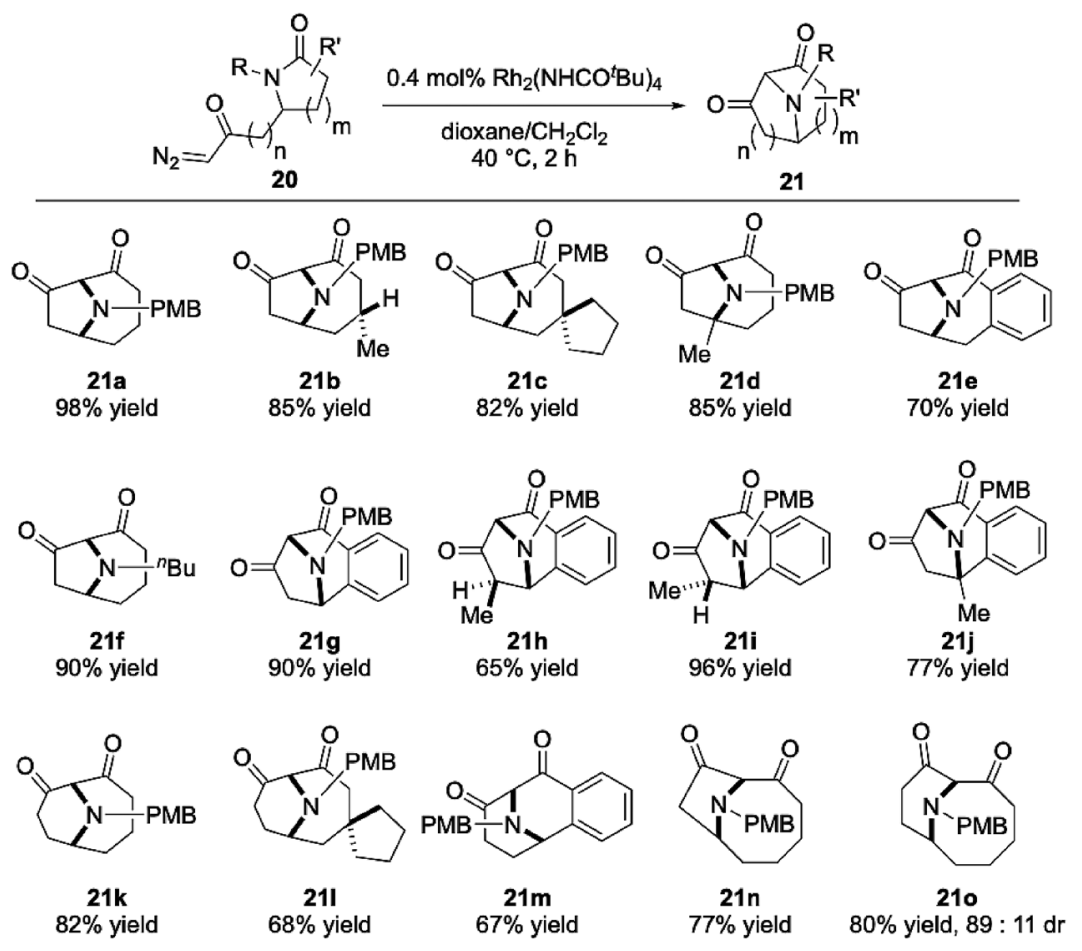

Fig. 11. Amide Insertion Reaction to Synthesize Azabicycloalkanes
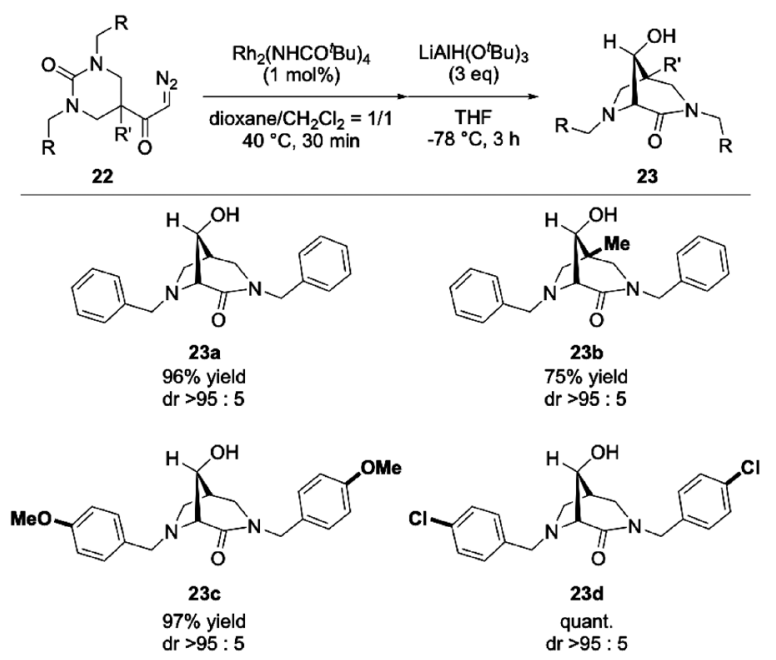

Fig. 12. Urea Insertion Reaction 
The dearomative spirocyclization of $\beta$-naphthols 17 under Ag catalysis using indoles as nucleophiles followed by an integrated oxidative treatment enabled a one-pot double dearomatization reaction (Fig. 9). The corresponding product 19a was detected as rotamers in the ${ }^{1} \mathrm{H}-\mathrm{NMR}$ measurements due to steric repulsion between the lactam unit and the indole ring. The substrate applicability of the oxidative dearomatization is shown in Fig. 9. Electron-rich and electron-poor indoles were available, affording $\mathbf{1 9 b}-\mathbf{h}$ in good yields with good stereoselectivity (79-95\% yield, $81: 19$ to $89: 11 \mathrm{dr}$ ). Due to difficult substrate preparation and limited generality, however, only $19 \mathrm{k}$ and $19 \mathrm{l}$ are shown as the scope of functionalized $\beta$-naphthols.

\section{Insertion Reaction into $\mathbf{C}-\mathbf{N}$ Bond}

The insertion reaction of a metal-carbene is a powerful and unique chemical transformation that interposes a carbon atom into various bonds ${ }^{7,26-29)}$ (Fig. 10). Numerous successes have been reported for the $\mathrm{C}-\mathrm{H}$ insertion (eq 1) and cyclopropa-

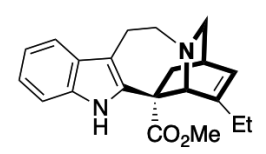

(+)-Catharanthine

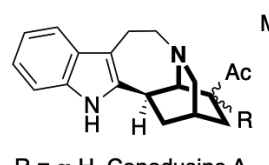

$\mathrm{R}=\boldsymbol{\alpha}-\mathrm{H}$ Conodusine $\mathrm{A}$ $\mathrm{R}=\boldsymbol{\beta}-\mathrm{H}$ Conodusine $\mathrm{B}$

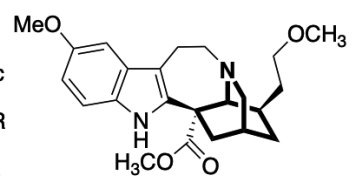

18-MC nation (eq 2, insertion into $\mathrm{C}-\mathrm{C}$ double bond) using a wide range of rhodium catalysts. Insertion reactions into amide $\mathrm{C}-\mathrm{N}$ bond had not been established when we initiated our studies of metal-carbene chemistry. ${ }^{30,31)}$ The reaction mechanism of the amide insertion proved to be related to Stevens rearrangement involving 1,2-functional group migration of

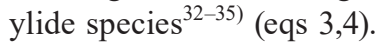

For the development of the amide insertion reaction, our group comprehensively surveyed known catalysts, but the results were unsatisfactory. Hence, a novel $\mathrm{Rh}_{2}\left(\mathrm{NHCO}^{t} \mathrm{Bu}\right)_{4}$ catalyst was designed and synthesized, achieving a highly chemoselective reaction to elaborate nitrogen-bridged frameworks. $^{36)}$ With the optimal catalyst in hand, the applicability of the amide insertion reaction was investigated with respect to the substrate (Fig. 11). To our delight, an array of azabicyclo[X.Y.1]alkane 21 could be synthesized in good to high yields by using $0.4 \mathrm{~mol} \%$ of $\mathrm{Rh}_{2}\left(\mathrm{NHCO}^{t} \mathrm{Bu}\right)_{4}$ catalyst $(\mathrm{X}=3-5, \mathrm{Y}=2,3)$. The amide insertion reaction involves nucleophilic attack of the nitrogen atom on the rhodium-carbene to form a metal-associated $N$-ylide ylide (eq 4). Therefore, substrates with an electron-donating PMB group on the nitrogen would exhibit a better performance relative to amide with alkyl substituent (21a vs. 21f). Of note, the ring system of 8-azabicyclo[3.2.1]octane and 9-azabicyclo[3.3.1]nonane core,

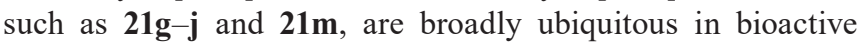
molecules and natural products. ${ }^{37)}$

In our development of the amide insertion strategy, the

Fig. 13. Indole Alkaloids with an Isoquinuclidine Skeleton

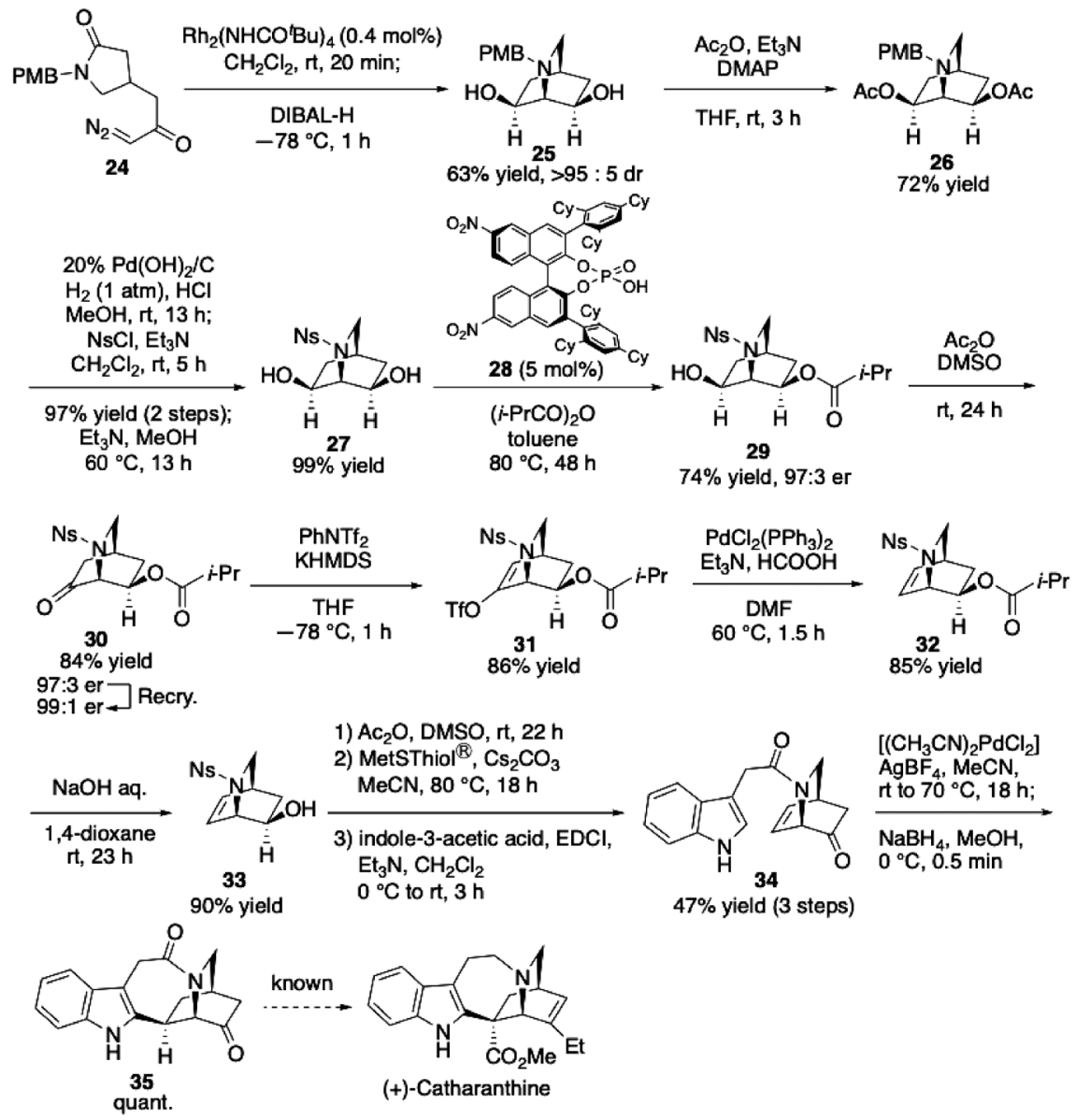

Fig. 14. Enantioselective Formal Synthesis of Catharanthine

Ns represents 2-nitrobenzenesulfonyl. 
amide group was activated by formation of the ylide equivalent to cleave the $\mathrm{C}-\mathrm{N}$ bond. After establishing a method to activate the amide functionality, analogous methodological expansion was then examined. Urea functionality is inherently robust and generally less reactive against oxidative or reductive conditions than the amide linkage. In the next study, an intramolecular urea insertion reaction to build up a diazabicyclo[3.2.1] octane core was performed (Fig. 12). Indeed, the reaction using $\mathrm{Rh}_{2}\left(\mathrm{NHCO}^{t} \mathrm{Bu}\right)_{4}$ complex under the conditions in dioxane/dichloromethane mixed solvent proceeded smoothly, providing the urea insertion product. ${ }^{38)}$ The obtained ketone, however, was unstable for moisture and silica gel, leading to the decreased yield after column chromatography for isolation. Thus, sequential transformations into isolable compounds were examined, and a simple one-pot reduction with reducing reagents proved feasible, providing the corresponding secondary alcohols $\mathbf{2 3}$ with a stereocontrol ( $>95: 5 \mathrm{dr}$ in all cases).

Synthetic applications of the developed metal-carbene reaction were also examined in our laboratory. Catharanthine possesses a ring system of azabicyclo[2.2.2]octane and is a member of Iboga class alkaloids (Fig. 13). The natural product has an impressive fused architecture that has attracted the attention of organic chemists and clinical researchers and can be transformed into vinblastine ${ }^{39)}$ which is used to treat some human tumors.

We initiated our synthetic studies by assembling meso-1,3-diol 25 via the amide insertion reaction using a $\mathrm{Rh}_{2}\left(\mathrm{NHCO}^{t} \mathrm{Bu}\right)_{4}$ catalyst $^{40)}$ (Fig. 14). After exchanging the protecting group with an Ns group on the tertiary amine, a desymmetrization reaction of $\mathbf{2 7}$ was performed by asymmetric acylation of the secondary alcohol based on the conditions developed by Professors Takasu and Yamada. The remaining hydroxy group of the obtained ester 29 was oxidized under Albright-Goldman conditions to give the resultant ketone 30, whose enantiopurity was enhanced through recrystallization. Subsequent triflation of $\mathbf{3 0}$ followed by a reductive treatment with $\mathrm{HCOOH} / \mathrm{PdCl}_{2}\left(\mathrm{PPh}_{3}\right)_{2}$ afforded alkene 32 in good yield. After basic hydrolysis of the ester and Albright-Goldman oxidation, an indole component was introduced by $N$-acylation $(\mathbf{3 2} \rightarrow \mathbf{3 4})$. An intramolecular Heck-type coupling reaction of 34 proceeded regioselectively, assembling the pentacyclic structure of catharanthine in an asymmetric format. ${ }^{41}$ )

\section{Conclusion}

We contributed to expanding metal-carbene chemistry through the development of novel methodologies, computation-guided mechanistic analysis, and synthetic applications for pharmaceutically important compounds. We found that silver-carbenes possess unusual chemical properties, leading to distinctive regio- and chemoselectivities. By taking advantage of the unique reactivities, the first highly enantioselective reaction of silver-carbenes was achieved in studies of arene dearomatizations. A novel insertion reaction against amide $\mathrm{C}-\mathrm{N}$ bonds was also developed using a $\mathrm{Rh}_{2}\left(\mathrm{NHCO}^{t} \mathrm{Bu}\right)_{4}$ catalyst, assembling an array of nitrogen-bridged heterocycles. Further investigation using the highly reactive species is in progress in our laboratory.

Acknowledgments I would like to express my deepest appreciation to Professor Tetsuhiro Nemoto (Chiba University) for his insightful guidance and fruitful suggestions, and for creating a relaxed research environment. I am particularly grateful to Professor Yasumasa Hamada, Masaya Nakajima, and all my co-workers whose names appear in the reference section for their enormous contribution to the present research achievement. Among them, Dr. Hiroki Nakayama, Dr. Masato Kono, Dr. Haruka Homma, Mr. Jun Ueda, Mr. Yoshinori Hashimoto, and Mr. Tsubasa Ito made critical contributions to the development of metal-carbene chemistry, as well as to the guidance and training of junior students. This work was financially supported by Takeda Science Foundation, Futaba Electronics Memorial Foundation, Uehara Memorial Foundation, Tokyo Biochemical Research Foundation, Chiba University SEEDS Fund, Ube Industries Foundation, Sasakawa Scientific Research Grant, Chugai Award in Synthetic Organic Chemistry, Iodine Research Project, Inohana Foundation, and Grantsin-Aid for Research Activity, Young Scientists (B), Scientific Research (C) from the Japan Society for the Promotion of Science. Numerical calculations were carried out on SR24000 at the Institute of Management and Information Technologies, Chiba University of Japan.

Conflict of Interest The author declares no conflict of interest.

\section{References}

1) Wang Y., Muratore M. E., Echavarren A. M., Chem. Eur. J., 21, 7332-7339 (2015).

2) Caballero A., Peŕez P. J., Chem. Eur. J., 23, 14389-14393 (2017).

3) Doyle M. P., Duffy R., Ratnikov M., Zhou L., Chem. Rev., 110, 704-724 (2010).

4) Davies H. M. L., Manning J. R., Nature (London), 451, 417-424 (2008)

5) Goto T., Takeda K., Shimada N., Nambu H., Anada M., Shiro M., Ando K., Hashimoto S., Angew. Chem. Int. Ed., 50, 6803-6808 (2011).

6) Wang B., Qiu D., Zhang Y., Wang J., Beilstein J. Org. Chem., 12, 796-804 (2016).

7) Lebel H., Marcoux J.-F., Molinaro C., Charette A. B., Chem. Rev., 103, 977-1050 (2003).

8) Miyazawa T., Suzuki T., Kumagai Y., Takizawa K., Kikuchi T., Kato S., Onoda A., Hayashi T., Kamei Y., Kamiyama F., Anada M., Kojima M., Yoshino T., Matsunaga S., Nat. Catal., 3, 851-858 (2020).

9) Ueda J., Harada S., Nakayama H., Nemoto T., Org. Biomol. Chem., 16, 4675-4682 (2018).

10) Liu Z., Sivaguru P., Zanoni G., Anderson E. A., Bi X., Angew. Chem. Int. Ed., 57, 8927-8931 (2018)

11) Wu W.-T., Zhang L., You S.-L., Chem. Soc. Rev., 45, 1570-1580 (2016).

12) Yanagimoto A., Komatsuda M., Muto K., Yamaguchi J., Org. Lett., 22, 3423-3427 (2020).

13) Wertjes W. C., Southgate E. H., Sarlah D., Chem. Soc. Rev., 47, 7996-8017 (2018)

14) Nemoto T., Ishige Y., Yoshida M., Kohno Y., Kanematsu M., Hamada Y., Org. Lett., 12, 5020-5023 (2010).

15) Nemoto T., Hamada Y., Yuki Gosei Kagaku Kyokaishi, 73, 977-986 (2015).

16) Nemoto T., Hamada Y., Synlett, 27, 2301-2313 (2016).

17) Nemoto T., Zhao Z., Yokosaka T., Suzuki Y., Wu R., Hamada Y., Angew. Chem. Int. Ed., 52, 2217-2220 (2013).

18) Nakayama H., Harada S., Kono M., Nemoto T., J. Am. Chem. Soc., 139, 10188-10191 (2017).

19) Harada S., Kwok I. M.-Y., Nakayama H., Kanda A., Nemoto T., $A d v$. 
Synth. Catal., 360, 801-807 (2018).

20) Yanagawa M., Kobayashi M., Ikeda M., Harada S., Nemoto T., Chem. Pharm. Bull., 68, 1104-1108 (2020).

21) Ikeda M., Nakayama H., Kanda A., Harada S., Nemoto T., Heterocycles, 103, 687-693 (2021).

22) Ueda J., Harada S., Kanda A., Nakayama H., Nemoto T., J. Org. Chem., 85, 10934-10950 (2020).

23) Ueda J., Harada S., Kobayashi M., Yanagawa M., Nemoto T., Eur. J. Org. Chem., 2021, 3999-4006 (2021).

24) Harada S., Kobayashi M., Kono M., Nemoto T., ACS Catal, 10, 13296-13304 (2020).

25) Homma H., Harada S., Ito T., Kanda A., Nemoto T., Org. Lett., 22 , 8132-8138 (2020).

26) Gillingham D., Fei N., Chem. Soc. Rev., 42, 4918-4931 (2013).

27) Gray E. E., Nielsen M. K., Choquette K. A., Kalow J. A., Graham T. J. A., Doyle A. G., J. Am. Chem. Soc., 138, 10802-10805 (2016).

28) Liu Z., Li Q., Yang Y., Bi X., Chem. Commun., 53, 2503-2506 (2017).

29) $\overline{\text { Otog N }}$., Chanthamath S., Fujisawa I., Iwasa S., Eur. J. Org. Chem., 2021, 1564-1567 (2021).

30) Spletstoser J. T., White J. M., Tunoori A. R., Georg G. I., J. Am. Chem. Soc., 129, 3408-3419 (2007).
31) Hie L., Fin Nathel N. F., Shah T. K., Baker E. L., Hong X., Yang Y.-F., Liu P., Houk K. N., Garg N. K., Nature (London), 524, 79-83 (2015).

32) West F. G., Naidu B. N., J. Am. Chem. Soc., 115, 1177-1178 (1993).

33) Vanecko J. A., Wan H., West F. G., Tetrahedron, 62, 1043-1062 (2006).

34) Padwa A., Chem. Soc. Rev., 38, 3072-3081 (2009).

35) Kono M., Harada S., Nemoto T., J. Synth. Org. Chem. Jpn., 77, 49-57 (2019).

36) Harada S., Kono M., Nozaki T., Menjo Y., Nemoto T., Hamada Y., J. Org. Chem., 80, 10317-10333 (2015).

37) Harada S., Kato R., Nemoto T., Adv. Synth. Catal., 358, 3123-3129 (2016).

38) Hashimoto Y., Kono M., Harada S., Nemoto T., Chem. Pharm. Bull., 66, 1041-1047 (2018).

39) Ishikawa H., Colby D. A., Boger D. L., J. Am. Chem. Soc., 130, 420-421 (2008)

40) Kono M., Harada S., Nozaki T., Hashimoto Y., Murata S., Gröger H., Kuroda Y., Yamada K., Takasu K., Hamada Y., Nemoto T., Org. Lett., 21, 3750-3754 (2019).

41) Moisan L., Thuéry P., Nicolas M., Doris E., Rousseau B., Angew. Chem. Int. Ed., 45, 5334-5336 (2006). 